\title{
Efecto del ácido linoleico conjugado sobre la proporción de sexos y calidad de embriones bovinos producidos in vitro"
}

\author{
Effect of conjugated linoleic acid on sex ratio and quality of in vitro \\ produced bovine embryos

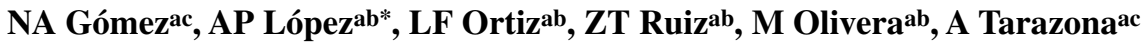 \\ aGrupo de investigación Biogénesis, Universidad de Antioquia, Antioquia, Colombia. \\ bFacultad de Ciencias Agrarias Universidad de Antioquia, Antioquia, Colombia. \\ cDPA/FCA Universidad Nacional de Colombia, Bogotá, Colombia.
}

\begin{abstract}
SUMMARY
The aim of this study was to evaluate the effect of culture medium supplementation with conjugated linoleic acid (CLA) on embryo cleavage, embryo production, sex ratio and embry o quality in in vitro produced bovine embryos at day 7 of culture. 308 COCs were used for the group supplemented with $100 \mu \mathrm{M}$ of the CLA isomer Cis-9 trans-11 and Cis-10-Trans-12 and 257 COCs for the untreated control group; the embryo production was $25.32 \%$ vs $35.40 \%$, respectively, with significant difference between them $(\mathrm{P}<0.05)$. The embryos were classified according to the IETS in $\mathrm{Mo}, \mathrm{Bt}, \mathrm{Bl}$ and $\mathrm{Bx}$ stages for morphological and molecular analysis. PCR was used for sex determination; embryo quality was assessed as grade 1 (excellent or good) and Grade 2 (regular). The results showed no significant difference in the proportion of embryos male:female for any of the stages in the CLA supplemented group achieving the expected natural ratio (50:50), while the control maintained a greater number of males. The CLA improved quality in $\mathrm{Bl}$ and $\mathrm{Bt}$ stages for both females and males $(\mathrm{P}<0.05)$ having a greater number of grade 1 embryos in supplemented group, while control embryos were more in grade 2. In conclusion, CLA adversely affects the production of bovine embryos in vitro, but the sex ratio equals the natural one in all stages and improves embryo quality in some stages of early development.
\end{abstract}

Palabras clave: bovino, CLA, calidad embrionaria, proporción de sexo.

Key words: bovine, CLA, embryo quality, sex ratio.

\section{INTRODUCCIÓN}

El reporte 2007 de la Sociedad Internacional de Transferencia de Embriones informó para ese año una producción mundial de 1.198.078 embriones transferibles, de los cuales $36 \%$ fueron producidos por fecundación in vitro (Thibier 2008). Algunos reportes demuestran que a partir de los embriones producidos in vitro se genera un mayor número de crías machos (Avery y col 1992, Wagtendonk-de Leeuw y col 1998, Numabe y col 2000, Camargo y col 2010), alterando la proporción natural de sexos (King y col 1991). Según Larson y col, los embriones macho producidos in vitro se desarrollan más rápido debido a su metabolismo acelerado, por lo contrario los embriones hembra parecen estar influenciados por las condiciones de cultivo teniendo un desarrollo más lento (Larson y col 2001), lo que ocasiona que al día 7 muchos embriones hembra no alcancen a clasificarse dentro de los estadios transferibles. Una posible explicación de lo anteriormente

Aceptado: 09.08.2012.

\# Departamento Administrativo de Ciencia, Tecnología e Innovación - Colciencias.

* 21 Carrera 75 \#65-87, Bloque 46 oficina 202, Ciudadela Robledo Universidad de Antioquia-Medellín, Colombia; angeladir7@gmail.com expuesto es que la inactivación tardía de uno de los dos cromosomas X en los embriones hembra (Bermejo-Álvarez y col 2010) permitiría la expresión por más tiempo de algunos genes ubicados en dicho cromosoma, entre los que se encuentra el de la glucosa 6 fosfato deshidrogenasa (G6PDH) (Camargo 2010); de esta forma se generaría un aumento en la concentración de esta enzima y por tanto un aumento en la ruta de la pentosa fosfato (Tiffin y col 1991), lo cual haría que los embriones hembra tuvieran un metabolismo con tendencia a la acumulación de energía en forma de gotas lipídicas (Abe y col 2002), mientras que los embriones machos tenderían a un metabolismo glucolítico con mayor producción de energía por la vía mitocondrial (Bermejo-Álvarez y col 2010). Por tanto, hay más embriones machos en estadios de desarrollo avanzados al día 7 de cultivo.

Con el fin de obtener un mayor número de embriones hembras se han desarrollado técnicas como el uso de semen sexado (Cran 2007, Peippo y col 2010). Sin embargo, aún se presentan algunos inconvenientes, dentro de los cuales están: bajo porcentaje de embriones (Wheeler y col 2006, Seidel Jr 2007, Oses y col 2009), disponibilidad limitada y alto costo del semen, entre otros (Wheeler y col 2006, Seidel Jr 2007). Otra alternativa es el diagnóstico preimplantatorio por biopsia embrionaria (Basille y col 2009), 
el cual tiene el inconveniente de ser una técnica costosa y que por ser invasiva (Garcia 2001, Soom y Boerjan 2002) puede ocasionar daños graves en el embrión (Underwood y col 2010). Con estas consideraciones se han desarrollado metodologías que se basan en mejorar la cinética del desarrollo de los embriones hembras, permitiéndoles mayor sincronía con el momento de la transferencia. La adición o manipulación de moléculas en los medios de cultivo son alternativas para cambiar la proporción de sexos a favor de las hembras, que actualmente constituye un tema de interés, y en el cual se ha investigado el uso de glucosa y ácidos grasos poliinsaturados (PUFA's) como el ácido linoleico conjugado (CLA) (Pereira y col 2007).

Los CLA son un grupo de isómeros del ácido linoleico, algunos de ellos han mostrado actividad anticancerígena (Cis-9, Trans-11 y Trans-10, Cis-12) (Kelley y col 2007), antidiabética (Cis-9, Trans-11 y Trans-10, Cis-12) y antilipogénica (Trans-10, Cis-12) (Evans y col 2002) en diferentes modelos animales. Los PUFA's son potentes inhibidores de la glucólisis y la lipogénesis de novo, a través de la regulación de genes implicados en estas vías como la glucosa 6 fosfato deshidrogenasa (G6PDH), L-piruvato quinasa (PK-L), ácido graso sintasa (FAS) y acetil-CoA carboxilasa (ACC) (Dentin y col 2005). Zhai y col demostraron en adipocitos que el isómero de CLA Trans-10, Cis-12 muestra una influencia sobre el metabolismo lipídico estimulando el gasto energético por oxidación de lípidos (Zhai y col 2010). Dentin y col demostraron en hepatocitos que algunos PUFA's como el ácido linoleico (AL), ácido eicosapentaenoico (EPA) y ácido docosahexaenoico (DHA) regulan la proteína respondedora de unión a carbohidratos (CHREBP), disminuyendo la expresión de FAS y ACC importantes en la vía de lipogénesis de novo (Dentin y col 2005). En embriones bovinos in vitro no se ha dilucidado el papel que juega el CLA en estas vías; sin embargo, se sabe que disminuye el diámetro de las gotas lipídicas mejorando la criorresistencia (Pereira y col 2008). Pereira y col al evaluar este parámetro encontraron una proporción de 52,2\% de machos y 48,8\% de hembras para el grupo control, mientras que en el grupo suplementado con CLA fue $45,5 \%$ vs $54,5 \%$ respectivamente, sugiriendo un efecto del CLA sobre la proporción de embriones macho:hembra bovinos producidos in vitro (Pereira y col 2008).

El objetivo del presente trabajo fue evaluar el efecto de la suplementación del medio de cultivo con CLA (isómeros Cis-9-Trans-11 y Cis-10-Trans-12), sobre el clivaje, la producción de embriones, la proporción de sexos y la calidad en embriones bovinos producidos in vitro al momento de seleccionarlos para su transferencia.

\section{MATERIAL Y MÉTODOS}

Se utilizaron medios comerciales para la maduración, fecundación y cultivo in vitro, marca Nutricell ${ }^{\circledR}$, (Campinhas, Brasil), suero fetal bovino (SFB) (Gibco, Invitrogen Corporation, Carlsbad, CA, USA), y para el lavado y selección de complejos cumulus ovocito (CCO) se utilizó Talp-Hepes. Todos los reactivos utilizados fueron adquiridos en Sigma (Sigma Aldrich, St. Louis, MO, USA).

\section{OBTENCIÓN DE LOS COMPLEJOS CUMULUS OVOCITO (CCO)}

Los CCOs se obtuvieron a partir de ovarios de hembras bovinas sacrificadas en la planta de beneficio local. Los ovarios se lavaron en solución salina estéril al 0,9\% a una temperatura de 36 a $37^{\circ} \mathrm{C}$ y fueron transportados hasta el laboratorio dentro de las dos horas siguientes a la colecta. Inmediatamente se realizó la aspiración de folículos entre 2 y $7 \mathrm{~mm}$ de diámetro mediante una jeringa de $10 \mathrm{ml}$ y aguja calibre $18 * 1 / 2$; el líquido folicular obtenido se depositó en un tubo cónico de $15 \mathrm{ml}$ y se dejó decantar por 20 minutos antes de hacer la selección de los CCO en medio de selección Talp-Hepes (Tarazona y col 2006). Los CCO fueron evaluados y clasificados por su morfología y sólo se utilizaron $\mathrm{CCO}$ de calidad 1 y 2 considerados aptos para maduración de acuerdo a lo informado por de Loos y col 1989 y Stojkovic y col 2001.

\section{MADURACIÓN IN VITRO DE LOS CCO}

La maduración se realizó en placas de petri en microgotas de $50 \mu \mathrm{l}$ de medio cubiertas con aceite mineral (10 $\mathrm{CCO}$ por gota) incubados por $24 \mathrm{~h}$ en mezcla de $6 \% \mathrm{CO}_{2}$ en aire, $38,6^{\circ} \mathrm{C}$, y humedad relativa $\geq 90 \%$.

\section{FECUNDACIÓN IN VITRO}

El semen criopreservado fue descongelado a $36^{\circ} \mathrm{C}$ por un minuto; se capacitó y separó en gradiente de Percoll 90/45 (Parrish y col 1995), se ajustó la concentración final a $2 \times 10^{6}$ espermatozoides por ml. Después de 24 h de maduración los CCO fueron lavados y denudados parcialmente por pipeteo repetido y puestos en gotas de $50 \mu \mathrm{l}$ de medio de fecundación previamente inseminadas y suplementadas con heparina $12 \mu \mathrm{l} / \mathrm{ml}$ y PHE $45 \mu \mathrm{l} / \mathrm{ml}$.

\section{CULTIVO IN VITRO}

Después de 18 a 20 horas de coincubación de los gametos, los presuntos cigotos fueron lavados para retirar las células de granulosa y se depositaron en medio de cultivo suplementado con $100 \mu \mathrm{M}$ de CLA (Cis-9 Trans-11 y Cis-10-Trans-12) (O5507 Sigma) durante los siete días de cultivo (Pereira y col 2007).

\section{EVALUACIÓN DE CLIVAJE}

A las 96 horas pos inseminación (hpi) se realizó la evaluación de clivaje inicial y se retiraron del cultivo aquellos que no iniciaron división, clivajes inferiores a cuatro células o embriones que presentan morfología compatible con apoptosis (Tarazona y col 2010 b). 


\section{DETERMINACIÓN DEL SEXO}

Para la extracción de DNA embrionario se empleó el kit DNeasy Blood \& Tissue ${ }^{\circledR}$ (QiAGEN) siguiendo las indicaciones del fabricante. La PCR se realizó empleando los primers BOV97M (F) 59-GAT CAC TAT ACA TAC ACC ACT y BOV97M (R) GCT ATG ACA CAA ATT CTG y un par de primers específicos para bovino, satélite 1.715 (F) TGG AAG CAA AGA ACC CCG CT y (R) TCG TCA GAA ACC GCA CAC TG, para la determinación del sexo (Park y col 2001). La mezcla para la reacción se realizó en un volumen final de $25 \mu \mathrm{l}$ que contenía $2,5 \mathrm{mM}$ de $\mathrm{MgCl}_{2}$, $200 \mu \mathrm{M}$ de cada deoxynucleósido trifosfato (dNTP), $1 \mathrm{X}$ de Taq buffer $10 \mathrm{X}$ con $\mathrm{KCl}(\mathrm{pH} 8,8), 1 \mathrm{U}$ de taq DNA polimerasa (Fermentas ${ }^{\circledR}$ ) y $0,3 \mathrm{mM}$ de cada primer BOV97M, $0,06 \mathrm{mM}$ de cada primer específico bovino, satélite 1.715 . La amplificación fue realizada en un total de 40 ciclos con el siguiente perfil térmico: $95^{\circ} \mathrm{C}$ por 30 segundos, $50{ }^{\circ} \mathrm{C}$ por 30 segundos y $72{ }^{\circ} \mathrm{C}$ por 5 minutos (Nedambale y col 2004). Debido a la baja concentración de DNA en las muestras (1 a $3 \mathrm{ng} / \mu \mathrm{l}$ ) fue necesario realizar una segunda PCR con un total de 30 ciclos empleando el mismo perfil térmico y utilizando $1 \mu \mathrm{l}$ del producto de la PCR anterior.

Los productos de la PCR fueron visualizados por electroforesis en gel de agarosa al 1,5\% con bromuro de etidio a una concentración de $0,5 \mu \mathrm{g} / \mathrm{ml}$ y evaluados bajo luz ultravioleta empleando un transiluminador. La amplificación de BOV97M, localizado en el cromosoma Y, produce un fragmento de $141 \mathrm{bp}$ y el específico bovino satélite 1.715 localizado en un autosoma genera un fragmento de 216 bp (Nedambale y col 2004). La presencia de ambos fragmentos en el producto de la PCR indicó que el sexo del embrión era macho y un único fragmento de 216 bp que el embrión era hembra.

\section{MÉTODO DE EVALUACIÓN DE CALIDAD MORFOLÓGICA:} DÍA 7 DE CULTIVO

Para la evaluación morfológica se empleó la clasificación de la IETS: mórula (Mo), blastocisto temprano (Bt), blastocisto (Bl) y blastocisto expandido (Bx). La calidad del embrión se determinó con los siguientes criterios: grado 1 (excelente o buena): embrión esférico con blastómeras de tamaño y color uniformes y zona pelúcida intacta, embrioblastos uniformes y localizados, blastoceles bien formados y células trofoectodérmicas periféricas planas; grado 2 (regular): embrión con alteraciones moderadas en la forma y tamaño de las blastómeras, color no uniforme en algunas células, presencia de picnosis o signos de apoptosis (Tarazona y col 2010 a); y embriones no viables aquellos con alteraciones mayores en la forma de la masa celular embrionaria o en el tamaño y color de las blastómeras, o detenidos en el desarrollo (Robertson y Nelson 1998). Posterior a la evaluación morfológica, los embriones fueron depositados en solución buffer de lisis del kit DNeasy Blood \& Tissue (QiAGEN) previa extracción de la zona pelúcida para su análisis molecular.

\section{ANÁLISIS ESTADÍSTICO}

El tipo de análisis empleado fue un diseño completamente aleatorizado unifactorial,

Con la finalidad de evaluar si la adición de CLA tuvo un efecto en el clivaje y la producción de embriones se realizó una prueba exacta para comparar los parámetros "P" para valores binomiales, para este análisis se utilizó el programa estadístico Stat Calc versión 2.0. Para evaluar el efecto del CLA sobre la proporción macho:hembra y la calidad de los embriones en cada uno de los estadios, se realizó una prueba exacta de Fisher; para este análisis se utilizó el programa estadístico SPSS versión 19 para Windows (SPSS Inc. Chicago IL, USA). El nivel de confianza seleccionado fue de $95 \%$, valores de $\mathrm{P}$ comprendidos entre el 0,05 y 0,1 fueron considerados como tendencias.

\section{RESULTADOS}

La suplementación del medio de cultivo con CLA afectó negativamente la tasa de clivaje y la tasa de desarrollo embrionario al día 7 de cultivo in vitro $(\mathrm{P}<0,05)$. Sin embargo no se observó un efecto $(\mathrm{P}>0,05)$ sobre la proporción macho:hembra de los embriones (cuadro 1).

Cuadro 1. Clivaje, producción de embriones y proporción de sexos al día 7 de embriones bovinos producidos in vitro cultivados en medio suplementado con CLA.

Cleavage, embryo production and sex rate on day 7 of in vitro produced bovine embryos culture in CLA supplemented medium.

\begin{tabular}{|c|c|c|c|c|c|c|c|c|c|}
\hline & \multirow{2}{*}{$\begin{array}{c}\text { CCO } \\
\text { Fertilizados }\end{array}$} & & \multirow{2}{*}{ Clivaje } & \multirow{2}{*}{\multicolumn{2}{|c|}{ Embriones día 7 (\%) }} & \multicolumn{4}{|c|}{ Sexo día 7 (\%) } \\
\hline & & & & & & & Hembras & & Machos \\
\hline & $(n)$ & (n) & $\% \pm \mathrm{DE}$ & $(n)$ & $\% \pm \mathrm{DE}$ & (n) & $\% \pm \mathrm{DE}$ & $(n)$ & $\% \pm \mathrm{DE}$ \\
\hline Control & 257 & $215^{\mathrm{a}}$ & $83,66 \pm 11,72$ & $91^{\mathrm{a}}$ & $35,40 \pm 1,16$ & $41^{\mathrm{a}}$ & $45,05 \pm 2,27$ & $50^{\mathrm{a}}$ & $54,94 \pm 2,29$ \\
\hline CLA & 308 & $234^{b}$ & $75,97 \pm 15,61$ & $78^{b}$ & $25,32 \pm 14,74$ & $39^{a}$ & $50 \pm 2,06$ & $39^{\mathrm{a}}$ & $50 \pm 2,20$ \\
\hline
\end{tabular}

a, b: Valores en la misma columna con diferentes superíndices difieren significativamente ( $\mathrm{P}<0,05)$. CLA: Ácido linoleico conjugado (Cis-9 Trans-11 y Cis 10-Trans-12), Valor P Clivaje $=0,0242$ y Valor P Embriones $=0,0092$, Valor P Hembras $=0,5292$ y Valor P Machos $=0,5268$, con 95\% de confianza. 
La adición de CLA favorece la calidad de embriones hembra grado 1 solamente en el estadio de blastocisto $(\mathrm{P}<0,05)$, logrando producir dos veces más embriones grado 1 comparado con el grupo control (12 vs 4) (cuadro 3).
Solamente para el estadio de blastocisto temprano se encontró que los embriones machos suplementados con CLA presentaban mejor calidad (grado 1) comparado con el grupo control; dicha diferencia fue estadísticamente significativa $(\mathrm{P}<0,05)$ (cuadro 4).

Cuadro 2. Proporción de sexos en los diferentes estadios de desarrollo al día 7 de embriones bovinos producidos in vitro cultivados en medio suplementado con CLA.

Sex rate in different development stages on day 7 of in vitro produced bovine embryos cultured in CLA supplemented medium.

\begin{tabular}{lccrrrr}
\hline \multirow{2}{*}{ Estadio día 7} & \multicolumn{2}{c}{ Control } & & \multicolumn{2}{c}{ CLA } & P value Fisher \\
\cline { 2 - 3 } \cline { 5 - 6 } & \multicolumn{1}{c}{ Hembras } & \multicolumn{1}{c}{ Machos } & & Hembras & \multicolumn{1}{c}{ Machos } & 0,099 \\
Mórula & $4(30,8 \%)$ & $9(69,2 \%)$ & & $12(60,0 \%)$ & $8(40,0 \%)$ & 0,160 \\
Blastocisto temprano & $10(50,0 \%)$ & $10(50,0 \%)$ & & $7(30,4 \%)$ & $16(69,6 \%)$ & 0,163 \\
Blastocisto & $14(46,7 \%)$ & $16(53,3 \%)$ & & $13(65,0 \%)$ & $7(35,0 \%)$ & 0,619 \\
Blastocisto expandido & $13(46,4 \%)$ & $15(53,6 \%)$ & & $7(46,7 \%)$ & $8(53,3 \%)$ & $39(50,0 \%)$ \\
\hline Total estadios & $41(45 \%)$ & $50(55 \%)$ & $39(50,0 \%)$ & $39(50)$ \\
\hline
\end{tabular}

$(\mathrm{P}>0,05)$.

Cuadro 3. Calidad embrionaria por estadio de desarrollo al día 7 de embriones bovinos producidos in vitro cultivados en medio suplementado con CLA.

Embryo quality by development stage on day 7 of in vitro produced bovine embryos culture in CLA supplemented medium.

\begin{tabular}{|c|c|c|c|c|c|}
\hline \multirow[b]{2}{*}{ Estadio } & \multicolumn{2}{|c|}{ CLA } & \multicolumn{2}{|c|}{ Control } & \multirow[b]{2}{*}{$P$ value Fisher } \\
\hline & $\begin{array}{c}\text { Hembras } 1 \\
(n)\end{array}$ & $\begin{array}{c}\text { Hembras } 2 \\
(n)\end{array}$ & $\begin{array}{c}\text { Hembras } 1 \\
(n)\end{array}$ & $\begin{array}{c}\text { Hembras } 2 \\
(n)\end{array}$ & \\
\hline Mórula & 9 & 3 & 2 & 2 & 0,547 \\
\hline Blastocisto temprano & 3 & 4 & 3 & 7 & 0,644 \\
\hline Blastocisto & 12 & 1 & 4 & 10 & $0,001^{\mathrm{a}}$ \\
\hline Blastocisto expandido & 7 & 0 & 13 & 0 & - \\
\hline Total estadios & 31 & 11 & 22 & 19 & 0,056 \\
\hline
\end{tabular}

$\mathrm{a}(\mathrm{P}<0,05)$

Cuadro 4. Calidad embrionaria por sexos y estadios de desarrollo al día 7 de embriones bovinos producidos in vitro cultivados en medio suplementado con CLA.

Embryo quality by sex and development stages of in vitro produced bovine embryos culture in CLA supplemented medium.

\begin{tabular}{|c|c|c|c|c|c|}
\hline \multirow[b]{2}{*}{ Estadio } & \multicolumn{2}{|c|}{ CLA } & \multicolumn{2}{|c|}{ Control } & \multirow[b]{2}{*}{$\mathrm{P}$ value Fisher } \\
\hline & $\begin{array}{c}\text { Machos } 1 \\
(n)\end{array}$ & $\begin{array}{c}\text { Machos } 2 \\
\text { (n) }\end{array}$ & $\begin{array}{c}\text { Machos } 1 \\
\text { (n) }\end{array}$ & $\begin{array}{c}\text { Machos } 2 \\
\text { (n) }\end{array}$ & \\
\hline Mórula & 4 & 4 & 2 & 7 & 0,335 \\
\hline Blastocisto temprano & 9 & 7 & 0 & 10 & $0,004^{\mathrm{a}}$ \\
\hline Blastocisto & 6 & 1 & 12 & 4 & 1 \\
\hline Blastocisto expandido & 8 & 0 & 15 & 0 & \\
\hline Total estadios & 27 & 12 & 29 & 21 & 0,276 \\
\hline
\end{tabular}

$\mathrm{a}(\mathrm{P}<0,05)$. 


\section{DISCUSIÓN}

El efecto negativo que tuvo la adición de CLA al medio de cultivo sobre el porcentaje de clivaje y de embriones obtenido en este estudio no ha sido informado previamente en embriones bovinos in vitro. Pereira y colaboradores son los únicos investigadores que han publicado acerca del uso del CLA en el cultivo de embriones bovinos in vitro; sus resultados no mostraron diferencia entre el grupo control y el suplementado con CLA $(100 \mu \mathrm{M})$ (Pereira y col 2008), contrario a lo encontrado en este estudio, donde la disminución en el porcentaje de clivaje y embriones del grupo CLA podría asociarse con diferentes rutas; en células dendríticas el isómero Cis-9 Trans-11 del CLA disminuyó la concentración nuclear del Factor Nuclear Khapa B (NFKb), y aumenta su concentración en el citosol (Reynolds y Roche 2010) regulando la vía de apoptosis inducida por NFKb, la cual es activa en embriones bovinos (Tarazona y col 2010 ). Esto podría ser una causa de la disminución en el porcentaje de embriones en presencia de CLA. Sin embargo, es importante esclarecer las rutas celulares mediadas por CLA en los embriones bovinos con el fin de comprender sus efectos durante el desarrollo embrionario temprano.

Algunos autores han informado que la producción de embriones in vitro modifica la proporción natural de sexos esperada (50:50) (King y col 1991), presentando generalmente un mayor porcentaje de embriones machos (Hasler y col 1995). Grisart evidenció que suplementos como el SFB favorecen el desarrollo de una mayor cantidad de embriones macho in vitro (Grisart y col 1995), mientras que Jiménez y col (2002) aumentando la concentración de glucosa obtuvieron más proporción de embriones hembra in vitro (Jiménez y col 2002). Lo anterior evidencia que la composición de los medios y los suplementos empleados en los protocolos de producción de embriones bovinos in vitro afecta la proporción de sexos de los embriones. Los resultados del presente trabajo muestran que la suplementación del medio de cultivo con CLA mantiene la proporción de sexos al día 7 de cultivo cuando se analizan los datos de forma global incluyendo todos los estadios, lo cual iguala la proporción natural; mientras que el grupo no suplementado presenta una mayor proporción de embriones machos (cuadro 1), lo cual concuerda con lo informado por Hasler y col (1995).

$\mathrm{Al}$ analizar los resultados de forma independiente para cada estadio de desarrollo, el análisis estadístico descriptivo mostró que el estadio de blastocisto presentó un mayor número de embriones hembra en el medio suplementado con CLA (cuadro 2). Los estadios de blastocisto y blastocisto expandido son ideales para la transferencia debido a que tienen una cinética normal de desarrollo embrionario temprano y una sincronía con el desarrollo del cuerpo lúteo de la hembra receptora, por lo cual son los estadios que informan los mejores porcentajes de preñez (Spell y col 2001). Para el estadio de mórula también hubo un mayor número de embriones hembras (cuadro 2), pero este estadio no es sincrónico con el desarrollo esperado para el día 7; a pesar de ello, las mórulas hembras producidas con CLA se podrían destinar a una transferencia más tardía o a receptoras cuyo cuerpo lúteo tuviese 6 días y no 7; como ya se ha informado exitosamente por Ling y colaboradores en 1995, esta sería una forma de aumentar las preñeces hembra a través de la suplementación de los medios de cultivo para embriones. La diferencia en proporción de hembras entre ambos grupos experimentales tomando el total de los estadios es 5,14\% a favor del grupo suplementado con CLA, que representó un aumento comparativo de cuatro embriones hembras transferibles, lo cual con un $30 \%$ de concepción reportado para transferencia de embriones por FIV (Peterson y Lee 2003) equivaldría a una hembra más nacida en cada proceso realizado.

Se sabe que la adquisición de la competencia para el desarrollo embrionario depende en gran medida de la maduración del ovocito (Duranthon y Renard 2000, Rodriguez y Farin 2004), esto afecta principalmente las divisiones mitóticas hasta estadios preimplantatorios y la calidad embrionaria (Tarazona y col 2010a, b). La calidad también puede ser modificada posterior a la fecundación mediante el uso de suplementos en los sistemas de cultivo (Lonergan y col 2006). Dentro de los suplementos, se sabe que las moléculas que modifican los ácidos grasos en la membrana afectan diferentes funciones estructurales, celulares e incluso vías de señalización (Spector y Yorek 1985, Talukdar y col 2005). Se ha informado que el uso de PUFA como el ácido linoleico (C18:2n-6) (Tominaga 2004), ácido araquidónico (C20:4n-6) y eicosapentaenoico (C20:5n-3) (Marques y col 2007) en los medios de cultivo han demostrado proporcionar mayor fluidez y versatilidad a las membranas (Zeron y col 2002, Spector y Yorek 1985), lo que estaría relacionado con una mejor calidad embrionaria y mayor criotolerancia (Marei y col 2010).

La suplementación con CLA en el medio de cultivo influyó en la calidad de los embriones hembra en el estadio de blastocisto $(\mathrm{P}<0,05)$ (cuadro 3), presentándose mayor número de embriones hembra grado 1 en el grupo suplementado con CLA (Cis-9-Trans-11 y Cis-10-Trans-12), en el presente trabajo. Lapa y colaboradores en 2011 demostraron que la suplementación con CLA durante la maduración mejora la competencia de los oocitos para el desarrollo de embriones de mejor calidad (Lapa y col 2011); sin embargo, aún no es clara la relación entre el CLA y el mejoramiento de la calidad de los blastocistos hembra. Asimismo Marques y col (2007) informan que la adición de otros PUFA como el ácido araquidónico (C20:4n-6) y eicosapentaenoico (C20:5n-3) en la maduración mejoran la calidad morfológica de los embriones producidos in vitro.

Los resultados obtenidos en la evaluación de los embriones machos indicaron una influencia del CLA sobre los embriones de calidad grado 1 en el estadio de blastocisto temprano $(\mathrm{P}<0,05)$ (cuadro 4). En términos comerciales, 
el parámetro de calidad es determinante para que un embrión sea o no transferido debido a que los embriones grado 1 tienen más probabilidades de generar gestaciones efectivas que los embriones grado 2 , dado que estos últimos tienen 4,11 veces más riesgo de desencadenar fallas en la implantación y por tanto pérdida de la preñez (Farin y Farin 1995). Lo anterior evidencia que el mejoramiento de la calidad embrionaria afecta la gestación y por este motivo en estudios posteriores se espera que la suplementación con CLA mejore los índices en los resultados de las gestaciones. En el presente estudio la producción de embriones en medio suplementado con CLA es menor al control (cuadro 1) y a los estándares mundiales, $30 \%$ a 40\% (Lonergan y col 2006, Humblot y col 2010); sin embargo, se evidenció una mayor calidad embrionaria con embrioblastos más uniformes y localizados (no dispersos), blastoceles bien formados y células trofoectodérmicas periféricas planas para embriones hembra en el estadio de blastocisto (figura 1) y en embriones macho en el estadio de blastocisto temprano.

Se evidencia que la suplementación con CLA tiene un efecto negativo sobre la producción de embriones bovinos in vitro; sin embargo, mantiene la proporción natural de sexos en el total de estadios y podría aumentar la cantidad de embriones hembra en los estadios de mórula y blastocisto; adicionalmente se presenta mayor calidad en el estadio de blastocisto para embriones hembra.

Los resultados presentados aquí abren las puertas a posteriores estudios sobre el efecto del CLA en diferentes rutas celulares que pueden mejorar la calidad, la criotolerancia y el desarrollo de embriones hembra.

\section{RESUMEN}

El objetivo de este estudio fue evaluar el efecto de la suplementación del medio de cultivo con ácido linoleico conjugado (CLA) sobre el clivaje, producción, proporción de sexos y calidad embrionaria en embriones bovinos producidos in vitro al día 7 de cultivo. Se fertilizaron 308 CCO suplementados en cultivo con $100 \mu \mathrm{M}$ del isómero de CLA Cis-9 Trans-11 y Cis-10-Trans-12 y 257 CCO en el grupo control; la producción de embriones fue $25,32 \%$ vs $35,40 \%$ respectivamente con diferencia significativa $(\mathrm{P}<0,05)$. Los embriones fueron clasificados por estadios según la IETS en Mo, Bt, Bl y Bx para su análisis morfológico y molecular. Se empleó PCR para la determinación del sexo y se evaluó la calidad como grado 1 (excelente o buena) y grado 2 (regular). Los resultados no muestran diferencia significativa en la proporción de sexos para ninguno de los estadios en el grupo suplementado con CLA; sin embargo, se igualó la proporción natural esperada (50:50), mientras que en el control hubo mayor cantidad de machos, al observar el total de los estadios. El CLA mejoró calidad en el estadio de B1 para las hembras y Bt para los machos $(\mathrm{P}<0,05)$, teniendo un mayor número de embriones grado 1 en los embriones suplementados, mientras que el control presentó más embriones grado 2. En conclusión, el CLA afecta negativamente la producción de embriones bovinos in vitro, pero iguala la proporción de sexos a la natural en el total de estadios y mejora calidad en algunos estadios del desarrollo temprano.

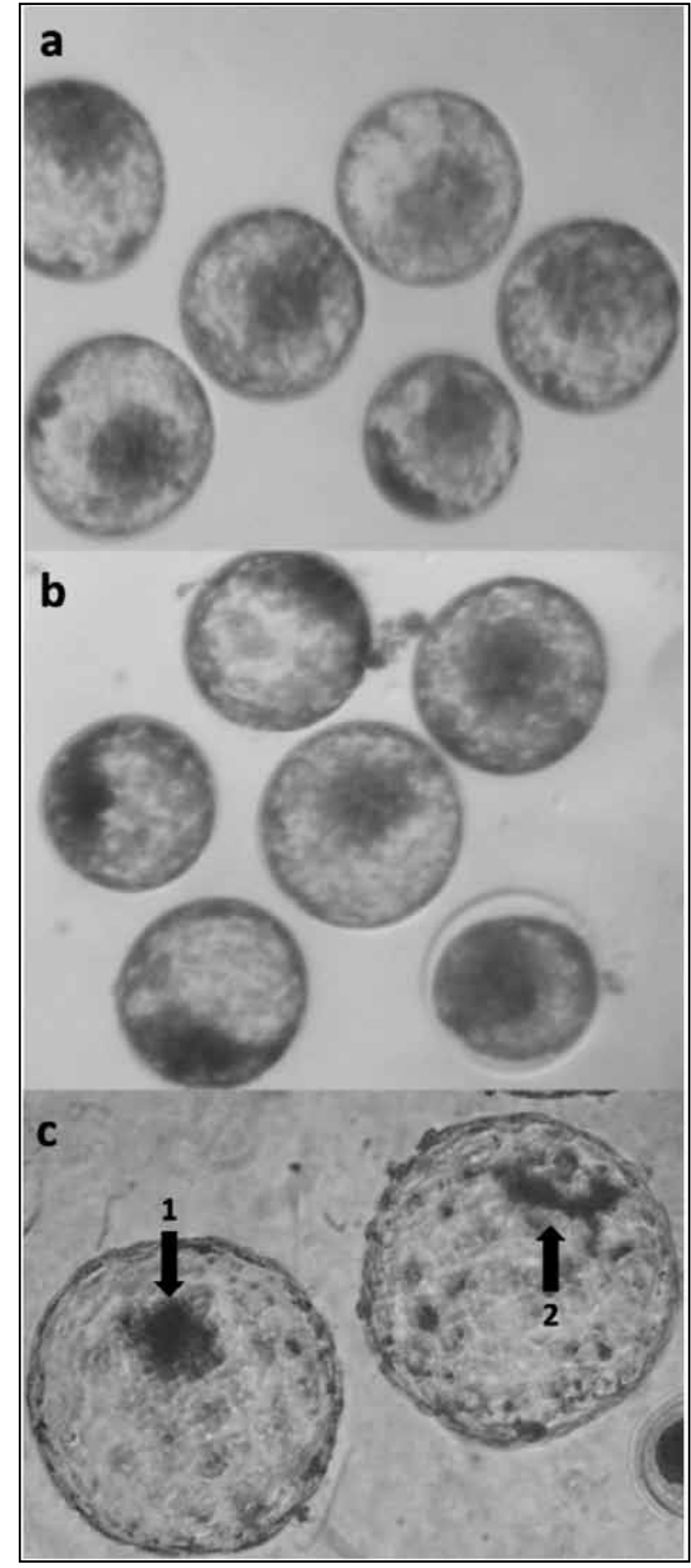

Figura 1. Evaluación morfológica de embriones. A: morfología embriones grupo control, B: morfología embriones grupo CLA, C: comparación embrioblasto uniforme (izquierda), embrioblasto disperso (derecha).

Embryo morphological evaluation. A: Embryo morphology in control group, B: Embryo morphology in CLA treated group, C: comparison of uniform embryoblast (left) and dispersed embryoblast (right). 


\section{AGRADECIMIENTOS}

Los autores agradecen a Colciencias por el apoyo económico, código proyecto 1115-452-21353; Al Grupo Biogénesis Universidad de Antioquia - Universidad Nacional, a la empresa privada Alianza Progenética, APG S.A.S.; a la Central Ganadera y a Colciencias "Programa Jóvenes Investigadores Virginia Gutiérrez".

\section{REFERENCIAS}

Abe H, S Yamashita, T Satoh, H Hoshi. 2002. Accumulation of cytoplasmic lipid droplets in bovine embryos and cryotolerance of embryos developed in different culture systems using serum free or serum containing media. Mol Reprod Dev 61, 57-66.

Avery B, CB Jørgensen, V Madison, T Greve. 1992. Morphological development and sex of bovine in vitro fertilized embryos. Mol Reprod Dev 32, 265-270.

Basille C, R Frydman, AE Aly, L Hesters, R Fanchin, G Tachdjian. 2009. Preimplantation genetic diagnosis: state of the art. Eur $J$ Obstet Gynecol Reprod Biol 145, 9-13.

Bermejo-Alvarez P, D Rizos, D Rath, P Lonergan, A Gutierrez-Adan. 2010. Sex determines the expression level of one third of the actively expressed genes in bovine blastocysts. Proc Natl Acad Sci 107, 3394-3399.

Camargo LSA, C Freitas, WF de Sa, A de Moraes Ferreira, RV Serapiao, JHM Viana. 2010. Gestation length, birth weight and offspring gender ratio of in vitro produced Gyr (Bos indicus) cattle embryos. Anim Reprod Sci 120, 10-15.

Camargo O. 2010. Efecto de la glucosa sobre la abundancia relativa de ARNm de genes lipogénicos en embriones bovinos machos y hembras producidos in vitro. Tesis Doctoral, Facultad de Ciencias Agrarias, Universidad de Antioquia, Antioquia, Colombia.

Cran DG. 2007. XY sperm separation and use in artificial insemination and other ARTs. Soc Reprod Fertil Suppl 65, 475-491.

De Loss F, C van Vliet, P van Maurik, AM Kruip. 1989. Morphology of immature bovine oocytes. Mol Reprod Dev 24, 197-204.

Dentin R, F Benhamed, JP Pégorier, F Foufelle, B Viollet, S Vaulont, J Girard, C Postic. 2005. Polyunsaturated fatty acids suppress glycolytic and lipogenic genes through the inhibition of ChREBP nuclear protein translocation. $J$ Clin Invest 115, 2843-2854.

Duranthon V, JP Renard. 2000. The developmental competence of mammalian oocytes: a convenient but biologically fuzzy concept. Theriogenology 55, 1277-1289.

Evans ME, JM Brown, MK McIntosh. 2002. Isomer-specific effects of conjugated linoleic acid (CLA) on adiposity and lipid metabolism. J Nutr Biochem 13, 508-516.

Farin PW, CE Farin. 1995. Transfer of bovine embryos produced in vivo or in vitro: survival and fetal development. Biol Reprod 52, 676-682.

Garcia J. 2001. Practical considerations of embryo manipulation: preimplantation genetic typing. Theriogenology 56, 1393-1399.

Grisart B, A Massip, L Collette, F Dessy. 1995. The sex ratio of bovine embryos produced in vitro in serum-free oviduct cell-conditioned medium is not altered. Theriogenology 43, 1097-1106.

Hasler J, W Henderson, P Hurtgen, Z Jin, A McCauley, S Mower, B Neely, L Shuey, J Stokes, S Trimmer. 1995. Production, freezing and transfer of bovine IVF embryos and subsequent calving results. Theriogenology 43, 141-152.

Humblot P, D Le Bourhis, S Fritz, JJ Colleau, C Gonzalez, C GuyaderJoly, A Malafosse, Y Heyman, Y Amigues, M Tissier, C Ponsart. 2010. Reproductive technologies and genomic selection in cattle. Vet Med Int 24, 192787.

Jiménez A, N Madrid-Bury, R Fernández, B Pintado, J De la Fuente, A Gutiérrez-Adan. 2002. Hyperglycemia- Induce apoptosis effects sex ratio of preimplantation embryos. Mol Reprod Dev 65, 180-187.

Kelley NS, NE Hubbard, KL Erickson. 2007. Conjugated linoleic acid isomers and cancer. J Nutr 137, 2599-2607.
King W, B Yadav, K Xu, L Picard, M Sirard, A Verini Supplizi, K Betteridge. 1991. The sex ratios of bovine embryos produced in vivo and in vitro. Theriogenology 36, 779-788.

Lapa M, C Marques, S Alves, M Vasques, M Baptista, I Carvalhais, M Silva Pereira, A Horta, R Bessa, R Pereira. 2011. Effect of trans 10 cis 12 conjugated linoleic acid on Bovine Oocyte Competence and Fatty Acid Composition. Reprod Domest Anim 46, 904-910.

Larson MA, K Kimura, HM Kubisch, RM Roberts. 2001. Sexual dimorphism among bovine embryos in their ability to make the transition to expanded blastocyst and in the expression of the signaling molecule IFN-tau. Proc Natl Acad Sci USA 98, 9677-9682.

Ling ZJ, DS Shi, HM Huang, YM Wei, RM Jiang, KH Lu. 1995. Pregnancy rate following transfer of IVF bovine embryos at different developmental stages. Theriogenology 43, 266.

Lonergan P, T Fair, D Corcoran, AC Evans. 2006. Effect of culture environment on gene expression and developmental characteristics in IVF-derived embryos. Theriogenology 65, 137-152.

Marei WF, DC Wathes, AA Fouladi-Nashta. 2010. Impact of linoleic acid on bovine oocyte maturation and embryo development. Reproduction 139, 979-988.

Marques C, M Baptista, M Vasques, A Horta, R Pereira. 2007. Effect of polyunsaturated fatty acids PUFA on bovine oocyte in vitro maturation and subsequent embryo development and freezability. Reprod Dom Anim 42, 108-109.

Nedambale TL, A Dinnyes, X Yang, XC Tian. 2004. Bovine blastocyst development in vitro: timing, sex, and viability following vitrification. Biol Reprod 71, 1671-1676.

Numabe T, T Oikawa, T Kikuchi, T Horiuchi. 2000. Birth weight and birth rate of heavy calves conceived by transfer of in vitro or in vivo produced bovine embryos. Anim Reprod Sci 64, 13-20.

Oses M, M Teruel, J Cabodevila. 2009. Utilización de semen bovino sexado en inseminación artificial, transferencia embrionaria y fertilización in vitro. Rev Vet 20, 138-145.

Park JH, JH Lee, KM Choi, SY Joung, JY Kim, GM Chung, DI Jin, KS Im. 2001. Rapid sexing of preimplantation bovine embryo using consecutive and multiplex polymerase chain reaction (PCR) with biopsied single blastomere. Theriogenology 55, 1843-1853.

Parrish JJ, A Krogenaes, JL Susko-Parrish. 1995. Effect of bovine sperm separation by either swim-up or Percoll method on success of in vitro fertilization and early embryonic development. Theriogenology 44 , 859-869.

Peippo J, M Raty, K Korhonen, M Eronen, K Kananen, T Hurme, M Halmekyto, A Maki-Tanila. 2010. Impact of in vitro fertilization of bovine oocytes with sex-sorted frozen-thawed spermatozoa on developmental kinetics, quality and sex ratio of developing embryos. Zygote 18, 185-194.

Pereira RM, MC Baptista, MI Vasques, AE Horta, PV Portugal, RJ Bessa, JC Silva, MS Pereira, CC Marques. 2007. Cryosurvival of bovine blastocysts is enhanced by culture with trans- 10 cis- 12 conjugated linoleic acid (10t, 12c CLA). Anim Reprod Sci 98, 293-301.

Pereira RM, I Carvalhais, J Pimenta, MC Baptista, MI Vasques, AE Horta, IC Santos, MR Marques, A Reis, MS Pereira, CC Marques. 2008. Biopsied and vitrified bovine embryos viability is improved by trans 10 , cis 12 conjugated linoleic acid supplementation during in vitro embryo culture. Anim Reprod Sci 106, 322-332.

Peterson AJ, RS Lee. 2003. Improving successful pregnancies after embryo transfer. Theriogenology 59, 687-697.

Reynolds CM, HM Roche. 2010. Conjugated linoleic acid and inflammatory cell signalling. Prostaglandins Leukot Essent Fatty Acids 82, 199-204.

Robertson I, RE Nelson. 1998. Certification and identification of the embryo. Manual of the international embryo transfer society (IETS) 3, 103-116.

Rodriguez KF, CE Farin, 2004. Gene transcription and regulation of oocyte maturation. Reprod Fertil Dev16, 55-67.

Seidel Jr G. 2007. Overview of sexing sperm. Theriogenology 68, 443-446. 
Soom A, M Boerjan. 2002. Assessment of mammalian embryo quality: invasive and non-invasive techniques. Kluwer Academic Publishers, Dordrecht, The Netherlands.

Spector AA, MA Yorek. 1985. Membrane lipid composition and cellular function. J Lipid Res 26, 1015-1035.

Spell AR, WE Beal, LR Cora, GC Lamb. 2001. Evaluating recipient and embryo factors that affect pregnancy rates of embryo transfer in beef cattle. Theriogenology 56, 287-297.

Stojkovic M, SA Machado, P Stojkovic, V Zakhartchenko, P Hutzler, PB Goncalves, E Wolf. 2001. Mitochondrial distribution and adenosine triphosphate content of bovine oocytes before and after in vitro maturation: correlation with morphological criteria and developmental capacity after in vitro fertilization and culture. Biol Reprod 64, 904-909.

Talukdar I, W Szeszel-Fedorowicz, LM Salati. 2005. Arachidonic acid inhibits the insulin induction of glucose-6-phosphate dehydrogenase via p38 MAP kinase. J Biol Chem 280, 40660.

Tarazona AM, JI Rodriguez, LF Restrepo, M Olivera-Ángel. 2006 Mitochondrial activity, distribution and segregation in bovine oocytes and in embryos produced in vitro. Reprod Domest Anim 41, 5-11.

Tarazona AM, A López, M Olivera-Ángel. 2010a. La competencia del oocito: qué, cómo y cuándo. Acta Biol Col 15, 3-18.

Tarazona AM, M Olivera-Ángel, YY Lenis. 2010 . Rol de la mitocondria y el estrés oxidativo en el bloqueo del desarrollo de embriones bovinos producidos in vitro. Arch Med Vet 42, 125-133.

Thibier M. 2008. The worldwide activity in farm animals embryo transfer. Data Retrieval Committee Statistics of Embryo Tranfer
Year. 2007. International Society Embrio Tranfer (IETS). Embryo Newsletter.

Tiffin G, D Rieger, K Betteridge, B Yadav, W King. 1991. Glucose and glutamine metabolism in pre-attachment cattle embryos in relation to sex and stage of development. Reproduction 93, 125.

Tominaga K. 2004. Cryopreservation and sexing of in vivo-and in vitro-produced bovine embryos for their practical use. J Reprod Dev 50, 29-38.

Underwood SL, R Bathgate, M Ebsworth, WM Maxwell, G Evans. 2010. Pregnancy loss in heifers after artificial insemination with frozen-thawed, sex-sorted, re-frozen-thawed dairy bull sperm. Anim Reprod Sci 118, 7-12.

Wagtendonk-de Leeuw V, AB Aerts, J Den Daas. 1998. Abnormal offspring following in vitro production of bovine preimplantation embryos: a field study. Theriogenology 49, 883-894.

Wheeler MB, JJ Rutledge, A Fischer-Brown, T Vanetten, S Malusky, DJ Beebe. 2006. Application of sexed semen technology to in vitro embryo production in cattle. Theriogenology 65, 219-227.

Zeron Y, D Sklan, A Arav. 2002. Effect of polyunsaturated fatty acid supplementation on biophysical parameters and chilling sensitivity of ewe oocytes. Mol Reprod Dev 61, 271-278.

Zhai J, Z Liu, J Li, JP Chen, L Jiang, D Wang, J Yuan, JG Shen, DP Yang, JQ Chen. 2010. Different mechanisms of cis-9, trans-11-and trans-10, cis-12-conjugated linoleic acid affecting lipid metabolism in 3T3-L1 cells. J Nutr Biochem 21, 1099-1105 